\title{
Application of Multinomial Logistic to Smallholder Farmers' Market Participation in Northern Ghana
}

\author{
Salisu Mustapha ${ }^{1}$, Mohammed Tanko ${ }^{2}$, Iddrisu Abukari ${ }^{1, ~ *}$ \\ ${ }^{1}$ Faculty of Communication and Agribusiness, Department of Agricultural and Resource Economics, Nyankpala Campus, University for \\ Development Studies, Tamale, Ghana \\ ${ }^{2}$ Faculty of Business and Law, Newcastle Business School, University of Newcastle, Newcastle, Australia
}

Email address:

mustaphasalis@hotmail.com (S. Mustapha),tanko201085@yahoo.com (M. Tanko), abuiddi100@gmail.com (I. Abukari)

*Corresponding author

\section{To cite this article:}

Salisu Mustapha, Mohammed Tanko, Iddrisu Abukari. Application of Multinomial Logistic to Smallholder Farmers' Market Participation in Northern Ghana. International Journal of Agricultural Economics. Vol. 2, No. 3, 2017, pp. 55-62. doi: 10.11648/j.ijae.20170203.12

Received: March 16, 2017; Accepted: March 27, 2017; Published: April 13, 2017

\begin{abstract}
The contribution of agriculture to the development of a country cannot be over emphasized, likewise the role played by smallholder farmers in the production of food in developing countries such as Ghana. Hence, the research examined the factors that affect market participation of smallholder farmers in Ghana. The Ghana Living Standard Survey data as published by the Ghana Statistical Service was employed and analyzed with the application of multinomial logistic regression model. Analysis of the data in the Northern part of Ghana indicate a very low market participation relative to the national average figure of $36 \%$ which itself is considered to be low at the international level. The results further show that, out of the total food crops produced (cereals), maize takes the highest whilst millet is the lowest cereal produced in Ghana. The results also revealed that only $24.2 \%$ of the total output of cereals produced in the study area is sold. The multinomial logistic results show that being a female farmer, having access to credit, increase in farm size and household size were factors that discourage subsistence farming and encourage market-oriented farming. The study recommends the promotion of small scale farmer participation in marketing of their produce through improving access to credit, land reallocation and promotion of female farmers' commercial participation.
\end{abstract}

Keywords: Food Production, Market Participation, Commercialization, Smallholder Farmers, Multinomial Regression

\section{Introduction}

Agriculture is a critical sector in the growth and development of many countries, and for a country to develop through industrialization, the key pillar or foundation should be agriculture. Agricultural sector functions as the food basket of a country, takes the greatest share in the GDP of many developing countries and employ over $50 \%$ of most developing countries' population [1]. The contribution made by the agriculture sector is achieved largely through the efforts of smallholder farmers who constitute majority in developing countries like Ghana. The agricultural sector in Ghana contributed more than $31.8 \%$ to GDP in the year 2009 , employed more than $42 \%$ of the working population in 2013 and provide food for the people in the country [2]. Despite this significant contribution of agriculture to the nation's development, the sector continues to decrease.
According to [2], the contribution of agriculture to GDP fell from $31.8 \%$ in 2009 to $19 \%$ in 2015 , and the contribution to employment fell by $3 \%$ in the same year. This is attributed to Ghana not giving attention to the agricultural sector, particularly to small scale farming.

Smallholder farming in Ghana is characterized by small land size farms which range from 0.5 to 2 hectares, food crops production for the purpose of consumption, use of simple farm tools such as hoes and cutlasses, and less participation in the marketing of their produce. Usually, surplus outputs are sold at the late time where prices are not attractive [1].

Currently, the government of Ghana with its plan to make the country attain an upper middle income status, proposed the policy of ensuring that the agricultural sector will lead the country to industrialization through irrigation agriculture and the expansion of farm size. This policy of increasing output without creating access to market for the farmers will 
undermine the sustainability of this policy. Hence, there is the need to commercialize the agricultural sector.

According to [3], commercialization can occur in both the input and output sides. [3] defined commercialization as the purchase of modern inputs and equipment, rise in marketed surplus and product choice based on profit maximization, substitution of inputs and output not traded for trade, creation of input and output markets, and specialization of the production of commodity which has comparative advantage. Based on this philosophy, commercialization can be defined as the ratio of the value of agricultural sale to the total value of agricultural production (output side). Alternatively, it can be approximated by the ratio of value of inputs purchased to the total value of agricultural products or inputs based on the market under consideration. [4] and [5] assert that, commercialization is the transformation of peasant agriculture from a subsistence economy known as production for home benefit to a more commercialized system (market based). For the transformation to take place, there must be a well-developed markets which should intend to promote economic growth and reduce poverty based on specialization, induced demand, efficient resource utilization, extraction of fund for industrial development and addressing food security challenges. The participation of small scale farmers in the marketing of output and purchasing of input in developing countries is insignificant, particularly in the output market.

Though some claimed that subsistent farmers are involved in the cultivation of traditional and food crops, hence, there is no need for commercialization, [6], [7], [8] and [9] notice that, commercialization is not limited to the selling of cash crop either in domestic market or foreign trade, but entails the allocation of significant amount to marketable commodity and giving a frequent market consideration to traditional commodities. With this understanding, smallholder farmers who engage in the production of traditional crops, mostly, food crop, can compete in the market for the growth of the country and as a means for the reduction of poverty in Ghana. This study is founded on the root of identifying the factors that determine the degree of participation of smallholder farmers who are into subsistence, transitional and commercial farmers, on the basis of the quantity of output sold in the market. The research finds it necessary to examine smallholder farmers' market participation because, policies that aim at promoting small scale subsistence farming into commercial farming should know the smallholder farmers' market participation level and the factors that determine the farmers' market participation to ensure that, food crops produced reach the final consumer.

\section{Methodology}

\subsection{Data Set}

The study employed a dataset of the Ghana Standard Living Survey (GLSS) published by the Ghana Statistical Service (GSS). The survey took place from the year 2012 and ended in 2013, however, the survey questionnaire and results was made available in the year 2014. The survey covered broad area of the country ranging from module one to module six. Areas survey covered include agricultural production of various crops, the various marketing process and channel, the consumption level of households, labor force and supply, nutrition level of house, the sanitation and shelter level, education and health among others. Though, the GSS published the report, the survey was conducted in collaboration with the World Bank (WB), the United Kingdom Department for International Development (UKDFID) and other research institutions in Ghana including Universities.

The research used the portion of the dataset that entails crop production and market participation of small scale farmers in Northern Ghana. To assess the factors affecting the smallholder farmers' market participation, the socio-economic characteristics of the farmers in the GLSS were employed.

\subsection{Empirical Model}

Determinants of smallholder farmers' market participation were evaluated through the adoption of an econometric model of crop output market participation index (MPI). The MPI is expressed as a function of household and household head characteristics $(\mathrm{HH})$, access to factors of production (AFP), access to markets (AM), access to transport infrastructure (AT), access to extension service (AES) and access to credit (AC). Mathematically, the market participation (MP) function is stated as:

$$
\mathrm{MP}=\mathrm{f}(\mathrm{HH}, \mathrm{AFP}, \mathrm{AM}, \mathrm{AT}, \mathrm{AES}, \mathrm{AC}, \mathrm{U})
$$

Where: $\mathrm{u}$ is an error term assumed to be independently and identically distributed with zero mean and constant variance.

The research compute household crop output market participation index in annual crops as equivalent of the proportion of the value of crop sold to the total value of crop produced. According to $[10]$, the crop-output MPI is computed using the formula:

$$
\boldsymbol{M P _ { i }}=\frac{\sum \overline{P_{k}} S_{i k}}{\sum \overline{P_{k}} Q_{i k}}
$$

Where:

$\mathrm{S}_{\mathrm{ik}}$ is units of $\mathrm{k}$ produced and sold by household $\mathrm{i}$ which is at an average community level price $\left(\mathrm{P}_{\mathrm{k}}\right)$ and $\mathrm{Q}_{\mathrm{ik}}$ is total units of produce $\mathrm{k}$ derived by household $\mathrm{i}$.

With the nature of market participation level $\left(\mathrm{MP}_{\mathrm{i}}\right)$, farmers were classified into subsistence farmers, thus, those whose percentage in terms of value sold is less than $25 \%$; transition farmers, farmers with a percentage value sold between $25 \%$ and $50 \%$ and commercial farmers, farmers with percentage of value sold above 50\%. Multinomial logistic regression was used in the estimation to ensure appropriate treatment of the three scenarios of market participation. [11] realized that, multinomial logistic method can be used to analyze the impact of various explanatory variables on the probability of being in one or another category (outcome) of farming. The merit of the Multinomial logistic 
model is that, it allows for the analysis of decisions across more than two categories such as the issues of three farmer groups and also gives permission for the determination of choice probabilities for different categories of the farmer groups.

Multinomial logistic regression is used to forecast the probability of category membership on a dependent variable among multiple independent variables which may either be dichotomous or continuous - interval or ratio in scale. Multinomial logistic regression is an advancement of the binary logistic regression to allow for more than two categories of the dependent or outcome variable. Similar to binary logistic regression, multinomial logistic regression is characterized by the employment of maximum likelihood estimation to evaluate the probability of categorical membership or contribution. The model does necessitate careful consideration of the sample size and finding out for outliers. In multinomial logistic model, multicollinearity should be evaluated by testing for simple correlations among the independent variables. In addition, assessment for multivariate outliers and for the exclusion of outliers is done with the aid of multivariate diagnostics which is a standard multiple regression. To [11], a minimum of 10 cases per independent variable is enough for a multinomial logistic regression as indicated by the sample size guidelines.

In multinomial logistic regression, the assumption of linearity, normality and homoscedasticity is often considered not to be important. Discriminant function which is a more powerful alternative to multinomial logistic regression requires the satisfaction of these assumptions. Multinomial logistic regression has been used more relative to discriminant function analysis due to the fact that, there is independence among the explanatory variables which ensures that membership in one group does not relate to the choice of another group, and the model also assume that if groups of the outcome variable are perfectly separated by the predictor(s), there is the tendency of having false coefficients that will be estimated and effect sizes will be greatly exaggerated than expected.

The specifications approach involved in multinomial logistic regression are not different to those used with standard multiple regression. The methods are used in situations in which when one dependent variable is used as criteria for choice on subsequent explained variables [11].

In explaining the multinomial logistic model, a random variable $(\mathrm{y})$ which takes the values $\{1,2 \ldots \mathrm{J}\}$ where $\mathrm{J}$ is a positive integer and a set of conditioning variables $(\mathrm{x})$ are used. In this research, y represents commercial class or categories of farmers engaged in selling of their produce and $\mathrm{x}$ contains household attributes like age, education, asset ownership among others. Holding other factors constant, at what level will the changes in the elements of $\mathrm{x}$ affect the probability of $y$. where $P(y=j / X), j=1,2, \ldots . J$. With the knowledge that probabilities must sum to unity, $P(y=j / x)$ is determined once the probabilities for $\mathrm{j}=1,2, \ldots \mathrm{J}$.

Let $\mathrm{x}$ be a $1 \times \mathrm{K}$ vector with first element unity. The multinomial logit model has response probabilities:

$$
\boldsymbol{p}\left(\boldsymbol{y}=\boldsymbol{j} / \boldsymbol{X}_{\boldsymbol{k}}\right)=\frac{\exp \left(\beta \boldsymbol{X}_{\boldsymbol{j}}\right)}{\left[1+\sum_{k=1}^{J} \exp \left(\beta \boldsymbol{X}_{\boldsymbol{K}}\right)\right]^{j=1 \boldsymbol{J}}}
$$

Where $\beta_{\mathrm{j}}$ is $\mathrm{Kx} 1, \mathrm{j}=1 \ldots \mathrm{J}$. Because the response probabilities must sum to unity,

$$
\boldsymbol{p}\left(\boldsymbol{y}=0 / \boldsymbol{X}_{\boldsymbol{k}}\right)=\frac{1}{\left[1+\sum_{k=1}^{J} \exp \left(\beta \boldsymbol{X}_{K}\right)\right]^{j=1 \boldsymbol{J}}}
$$

When $\mathrm{J}=1, \beta_{1}$ is the $\mathrm{Kx} 1$ vector of unknown parameters, through which the binary logit model is obtained. This research has three outcome or response probabilities, namely: subsistence farmers, transition farmers and commercial farmers.

For parameter estimates in equation (1) to be unbiased and consistent, the multinomial logistic regression requires the assumption of independence of irrelevant alternatives (IIA) to exist and the independence of irrelevant alternatives (IIA) assumption requires that the probability of being in one category by a given farmer needs to be independent from the probability of being in another commercial class - the probability of a farmer staying in one commercial group must hold. The independence of irrelevant alternatives is built on the premise of the independent and homoscedastic disturbance terms of the basic model in equation (1).

Estimates of the multinomial logistic regression model provide only the direction of the effect of the independent variables on the response variable. However, neither the magnitude of change nor probabilities of the parameters effects to the response variable is shown. It is very difficult to interpret the magnitudes of the coefficients in multinomial analysis. Hence, the decision left is to either compute partial effects in equation (5), or alternatively, compute differences in probabilities which relies on comparing fitted probabilities after multinomial logit estimation. [11] stated that, the critical issue of the fitted probabilities is that, it can be used for prediction purposes which can be used to obtain the correct percent predicted by category if need be. Therefore, the partial effects of the explanatory variables is given by differentiating equation (1) with respect to the explanatory variables as shown in equation (5):

$$
\frac{\alpha \boldsymbol{P}(\boldsymbol{y}=\boldsymbol{j} / \boldsymbol{X})}{\boldsymbol{a} \boldsymbol{X}_{k}}=\boldsymbol{p}\left(\boldsymbol{y}=\boldsymbol{j} / \boldsymbol{X}_{k}\right)\left\{\beta_{j k}=\frac{\left[1+\sum_{k=1}^{J} \beta_{h k} \exp \left(\beta_{k} \boldsymbol{X}\right)\right]}{\boldsymbol{g}(\boldsymbol{X}, \boldsymbol{\beta})}\right\}
$$

Where $\beta_{\mathrm{hk}}$ is the $\mathrm{k}^{\text {th }}$ element of $\beta_{\mathrm{h}}$ and

$$
\boldsymbol{g}(\boldsymbol{X}, \boldsymbol{\beta})=1+\sum_{h=1}^{J} \exp \left(X \beta_{h}\right)
$$

To know the change in the probability of a specific farm group with respect to a unit change in the independent variable, the marginal effects or marginal probabilities which 
are the functions of the probability itself were computed. With this method, the factors that differentiate the commercialization level of the households were known, discussed and explained to achieve the aim of the research.

With the help of Stata 14.1, the fitness of the multinomial model using both the model chi-square and the McFadden's Pseudo R-square was determined. Data of 136 households from the GLSS was run in multinomial logit model after capturing the hidden characteristics of the data by applying econometric analysis. This methodology is an advancement of the analysis of market participation as previous studies on market participation have typically adopted a two-step analytical method which involved unobservable decision to participate and the observed degree or intensity of participation in the markets by respondents.

Table 1. Description of explanatory variables.

\begin{tabular}{lll}
\hline Variable & Description & Unit of Measurement \\
\hline Age & Age of a farmer & Years \\
Household size & Household size of farmer & Number of household members \\
Education & The level of education of a farmer & Years \\
Sex & Gender of farmer & Dummy: male=1 and female=0 \\
Extension & No of visit by extension officer & Number of days \\
Credit & participating in credit activities & Dummy: yes=1 and Otherwise=0 \\
Seed & Quantity of seed & Kg \\
Seed expense & Amount spent on seed & GH $\phi$ \\
Water Harvesting & Quantity of water harvest & Liters \\
Farm size & Size of land & Hectares \\
Hired labor & Number of men hired & Man hours \\
Labor expense & Amount spent on hired labor & GH $\phi$ \\
Fertilizer & Quantity of fertilizer applied & Kg \\
\hline
\end{tabular}

\section{Results and Discussion}

\subsection{Crop Production, Sales, and Degree of Market Participation}

Ghana is involved in the cultivation of different cereal crops whose production continue to increase as many use cereal crops to process varied food for consumption. From statistics, it indicates that, the production value for cereals in metric tons for the year 2014 stood at 2,780,040. Figure 1 below illustrates the production figures for cereals in Ghana over the past 53 years. From the graph, the production of cereals reached a maximum value of 2,906,712 in 2010 and a minimum value of 388,943 in 1965 for the time period under consideration [12].

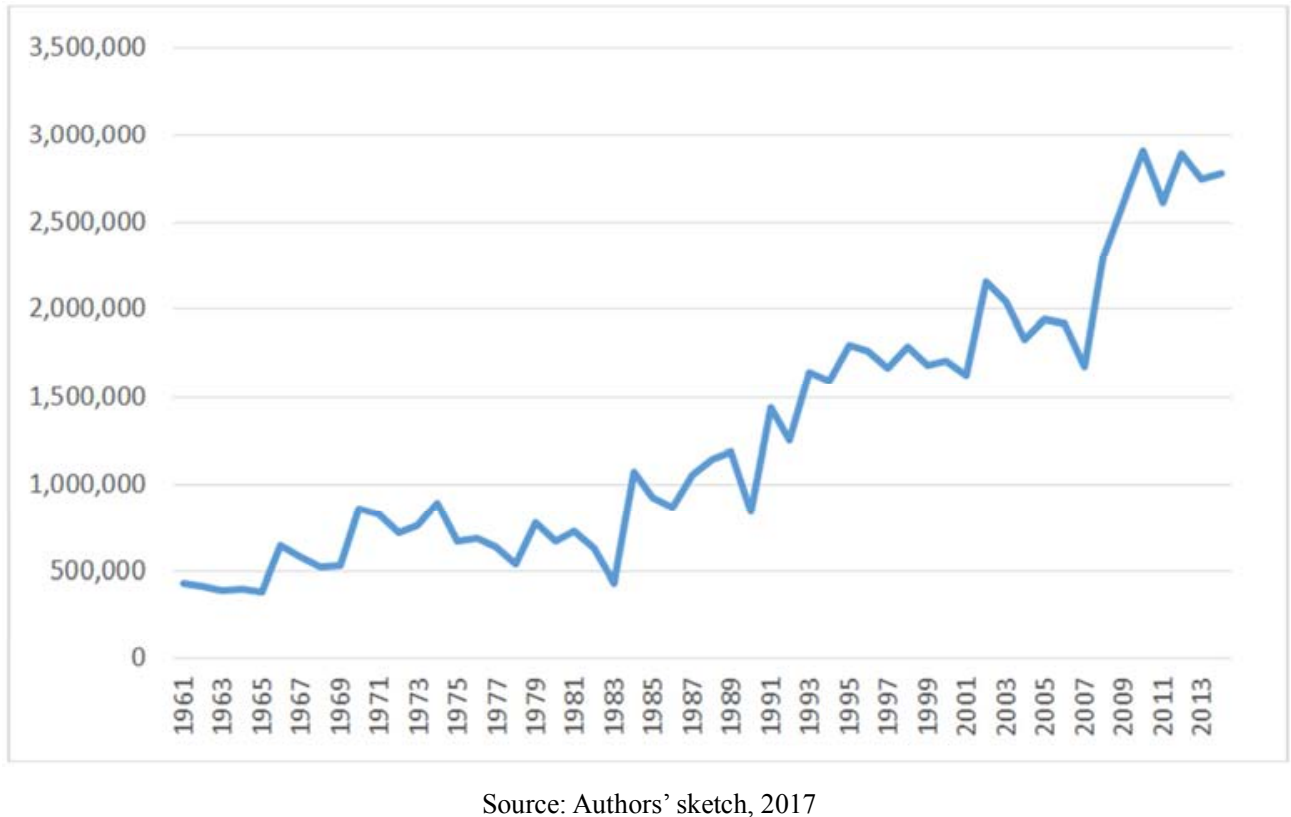

Figure 1. Trend of food production in Ghana (1961 - 2014).

From the GLSS data, analysis shows that, maize has the greatest share $(62 \%)$ of the total cereal crop production in the entire sample size of 136 . This is in line with the country's production records where maize for the past five decades is the leading cereal crop produced in Ghana. Next to maize in terms of cereal production for the survey is rice which comprised $17 \%$, sorghum took the third place in terms of volume of production and millet was last with $12 \%$ and $9 \%$ 
of the volume of cereal production respectively. The information is presented in Figure 2:

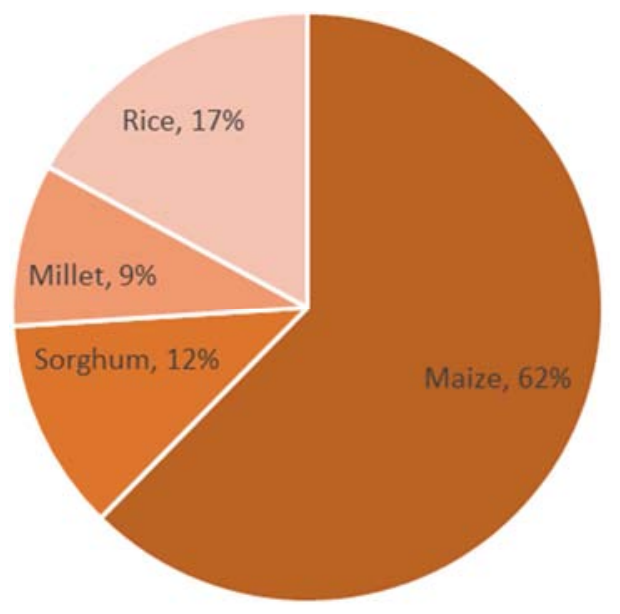

Source: Authors'sketch, 2017

Figure 2. Food production from GLSS.

Summary of statistics for the 136 households presented in Table 2 shows that, a typical household head produced food crops ranging from 163 to 42632 metric tons with an average of 24672.25 tons. Out of the total food crop produced, some are consumed and others were sold. From sales dimension, an average of 8948.95 tons were sold which also indicates a minimum of zero and maximum of 15385 tons respectively. Percentage of the gross value of all crops sold to the gross value of all crop produced with respect to the survey figures which this research refer to as degree of market participation indicates an average of 0.242 for the entire observation with a minimum of zero and maximum of one as it is a probability. Household heads who are in the commercialized class sold about $100 \%$ of the gross value of its total cash crop production, usually, rice and sorghum. However, market participation level in the study area is not encouraging and is lower than the national average which is about $36 \%$ [12]. The results show that, the level of market participation in the study area, which is $24.2 \%$, is a very low figure, worse than the national average of $36 \%$ which many policy analysts consider to be low.

Table 2. Descriptive statistics of food crop produced and sold.

\begin{tabular}{llllll}
\hline Variable & Obs. & Mean & Min & Max. & Stand. Dev. \\
\hline $\begin{array}{l}\text { Total food crop } \\
\text { produced }\end{array}$ & 136 & 24672.25 & 163 & 42632 & 1254.85 \\
$\begin{array}{l}\text { Total food crop sold } \\
\text { Market participation }\end{array}$ & 136 & 8948.95 & 0 & 15385 & 235.32 \\
$\begin{array}{l}\text { of food crop } \\
\begin{array}{l}\text { Degree of food crop } \\
\text { market participation }\end{array}\end{array}$ & 136 & 0.242 & 0 & 1 & 0.21 \\
\hline
\end{tabular}

Source: Field Survey, 2016.

\subsection{Application of Multinomial Logit to Factors Affecting the Degree of Market Participation}

The research tested to know whether the assumption of independence of irrelevant alternative (IIA) holds in the model using the Hausman test, and the result consistently indicate an affirmative, that, the assumption of IA is not violated. This suggests that, the application of multinomial logit model is appropriate. Also, the likelihood ratio statistics as indicated by chi-square statistics is highly significant, as indicated by a probability value of 0.0000 . This means that, the multinomial logit model has a strong explanatory power. Specification fitness of the data shows that, the variables included in the model explain $64.2 \%$ of the fluctuations in the degree of market participation of farmers as shown by the Pseudo R-square of value 0.6423. Table 3 shows the optimum tendency parameter estimates for the multinomial logistic regression in the case where a farmer is in commercial, transition and subsistence marketing.

Results of the multinomial logit regression revealed that most of the variables tested for the probability to sell more than $50 \%$ of the produce (commercial farmer) had met the a prior expected sign. Few variables such as age of respondent, education, seed expenses, hired labor and labor expenses had negative sign showing an inverse relation to market participation of commercial farmers. Among the inversely related factors, only seed expenses was significant at $10 \%$ significant level, the rest were insignificant. The remaining factors were positively related to commercial farmers' market participation, though some of them were not significant. The household size of a farmer, participation in credit facilities and the size of farm were the positive factors that affect commercial farmers' market participation. For transitional farmers, being a female farmer and participating in credit were the only factors that positively affect transitional farmers' market participation at $1 \%$ and $5 \%$ respectively. But, household size and farm size which had unexpected sign were inversely related to transitional farmers' market participation at significant level of $10 \%$ and $5 \%$ respectively. On the part of subsistent farmers (who sell below 25\% of their farm produce), market participation is positively associated with credit, farm size and the farmer being a female. The factors were significant and show improvement in market participation for subsistent farmers. However, the household size of the farmers indicates an inverse relationship with market participation which is the expected sign as the larger the household size, the lesser the produce available for sales in the case of a subsistent farmer.

It is critical to emphasize that, parameter estimates of the multinomial model provide only the direction of associations of the effect of the independent variables on the dependent variable without giving the actual magnitude of change or probabilities. So, the marginal effects which appear in the second, fifth and eighth column of the Table 3 aid to measure the expected change in probability of a particular category with respect to a unit change in an independent variable. The marginal effects show a varied results from subsistence to commercial farmers based on the sign and level of significance.

Considering household size, it decreases the chance of being a subsistence and transition farmer and increase the chance or tendency of being a commercial farmers. Also, 
being a male household head increases the probability of being subsistence farmer and have negative effect on being transition and commercial farmer as shown by their signs. Though, age was not significant, an increase in age by one year decreases the probability of being subsistence farmer while increasing the probability of being transition farmer and commercial farmer.

Table 3. Marginal effects of the explanatory variables on the probability of different market participation.

\begin{tabular}{|c|c|c|c|c|c|c|c|c|c|}
\hline \multirow[t]{2}{*}{ Variable } & \multicolumn{3}{|l|}{ Subsistence farmer } & \multicolumn{3}{|l|}{ Transition farmer } & \multicolumn{3}{|c|}{ Commercial farmer } \\
\hline & Marginal effects & Stand. Error & $\mathbf{P}>\mathbf{Z}$ & Marginal effects & Stand. Error & $\mathbf{P}>\mathbf{Z}$ & Marginal effects & Stand. Error & $\mathbf{P}>\mathbf{Z}$ \\
\hline Age & -0.032 & 0.015 & 0.135 & 0.028 & 0.074 & 0.148 & 0.024 & 0.031 & 0.122 \\
\hline Household size & -0.073 & 0.004 & $0.001^{\wedge}$ & -0.211 & 0.142 & $0.056^{*}$ & 0.032 & 0.004 & $0.005^{\wedge}$ \\
\hline Education & -0.203 & 0.057 & 0.132 & 0.064 & 0.074 & 0.532 & -0.053 & 0.024 & 0.312 \\
\hline Sex & -0.032 & 0.008 & $0.005^{\wedge}$ & 0.427 & 0.132 & $0.002^{\wedge}$ & 0.146 & 0.075 & 0.264 \\
\hline Extension & 0.023 & 0.010 & 0.156 & 0.278 & 0.257 & 0.131 & 0.085 & 0.027 & 0.367 \\
\hline Seed & 0.039 & 0.042 & 0.534 & 0.004 & 0.012 & 0.255 & 0.042 & 0.013 & 0.365 \\
\hline Seed expense & 0.004 & 0.006 & 0.256 & 0.032 & 0.074 & 0.165 & -0.063 & 0.017 & $0.064 *$ \\
\hline Water harves. & 0.128 & 0.073 & 0.136 & 0.054 & 0.003 & 0.632 & 0.032 & 0.053 & 0.164 \\
\hline Farm size & 0.029 & 0.024 & $0.076^{*}$ & -0.023 & 0.002 & $0.031+$ & 0.034 & 0.003 & $0.026+$ \\
\hline Hired labour & 0.009 & 0.011 & 0.367 & 0.007 & 0.236 & 0.146 & -0.032 & 0.014 & 0.436 \\
\hline Labour exp. & -0.013 & 0.003 & 0.271 & -0.015 & 0.057 & 0.356 & -0.052 & 0.031 & 0.367 \\
\hline Fertilizer & -0.053 & 0.002 & 0.156 & 0.231 & 0.074 & 0.217 & 0.022 & 0.003 & 0.185 \\
\hline
\end{tabular}

$*,+, \wedge$ : refers to significance at 10,5 , and $1 \%$ level, respectively.

Source: Field Survey, 2016

The results partly contradicts with previous research in some aspects and partly conformed or is consistent with other previous findings. For instance, [13] and [14] in their finding showed that men are likely to sell more grain early in the season-during the harvesting season at which time they think prices are still high and women prefer to store more output for household self-sufficiency. In this research, the opposite is true, men rather store more output for household selfsufficiency and wait for surplus while women household sell during the time of harvest as most women household heads have less dependents compared to male household heads. But the age which indicates more opportunity for commercial and transitional farmers in its increment is in line with [14], who explained that experience on farm work is proxy to age of farm household head which has a positive significant effect on the level of market participation by commercial farmers. [15] also shows that age of the household head negatively and significantly affects the degree of market participation by subsistence farmers. Meaning the older a subsistence farmer grows to [15], the more they have access to a better price information. Hence, their chance of participating more in marketing their produce.

Fertilizer usage has positive effect on the probability of being transition farmer and commercial farmer but decreases the probability of being subsistence farmer though was not significant at even $90 \%$ confident level. A one percent increase in fertilizer application of a household decreases the probability of being subsistence farmer by 5.3 percent but increases the probability of being transition and commercial farmer by 2.31 and 2.2 percent respectively. The results suggest that, the use of fertilizer integrates the farmer into the input market and not necessarily the output market as it is shown.

Participation in credit facilities and farm size were positively related to subsistence and transitional farmers as well as commercial farmers' participation in marketing of their produce. A subsistence farmer who has access to credit has a tendency of participating in market by $1.2 \%$ whilst the tendency for a transitional and commercial farmer to participate in marketing will increase by $1.3 \%$ and $3.1 \%$ respectively. Also, a unit increase in the land size of a subsistence farmer is likely to increase the farmer's market participation by $2.9 \%$ while transitional and commercial farmers' market participation is likely to increase by $2.3 \%$ and 3.4\% respectively. This result is in line with [16], [15] and [17] who notice that, credit which improves the purchasing power of a farmer and allows a farmer to use improved seeds to improve the productivity and increase in production has a positive significant impact on the degree of market participation. [18] used different model and the results indicate that, land size has a significant positive impact on the degree of market participation and this is due to the fact that, cultivated land size positively influences the share of sales from total production. To [18], households that possess greater or larger land size are relatively better off because it allows the household to have an excess supply from production for home consumption- output produced is above subsistence needs and this enable farmers to sell products in the market available at their disposal. This means, improving farmers' access to land can be a measure of enhancing or improving all the categories of farmers' market participation in Ghana.

\section{Conclusion and Recommendation}

Participation in market by smallholder farmers is getting priority, especially in the developing world in general. The need for Ghana to develop using the agricultural sector as the engine of growth has motivated the participation of many 
smallholder farmers in marketing their produce. In Ghana, smallholder farmers cultivate over $60 \%$ of the total cropped land and produce more than $75 \%$ of the total agricultural output [1]. Considering the agricultural led industrialization strategy for development and the dominance of smallholder agriculture in Ghana, it is important for smallholder farmers to be transformed from the subsistence based production where they concentrate production for house consumption, to a market oriented production system popularly called commercial agriculture. But, research shows that, Ghana's level in terms of agricultural market participation is at the infant stage compared to the country's position as a lowmiddle income country as ranked by the World Bank.

This research examined expected factors affecting the degree of market participation of smallholder farmers in Northern Ghana using the Ghana Living Standard Survey (GLSS) data published by the Ghana Statistical Service (GSS) in the year 2014. Farmers were classified into subsistence, transitional and commercial on the basis of the percentage of output they sold in the market which can be used to determine the income-poverty reduction level of the farmer, ability to transport, store and sell their products in the market participation process. In Ghana, empirical works show that production of peasant farmers could be increased through land and input use, to be specific, application of fertilizer and adoption of improved seed. However, farmers' participation in selling their produce has been low due to the employment of outmoded technology in agriculture leading to low yield, uncompetitive markets and weak rural infrastructures (transportation) linkage.

The findings show that, households in the study area are characterized by a high productivity and more chance of expanding agricultural output, but market participation has been low. On average, food produce's share that was sold in the market was found to be $24.2 \%$ of total food crop productions in the survey. Participants in the survey, particularly in Northern Ghana had high production with low degree of input and technology application relative to other areas. However, the degree of market participation was very low when compared with the national average of $36 \%$ which by international standard is also low. This gives a clear indication of the low level of market participation in the study area, the regions considered to be the largest in the country and has the potential to increase the country's foreign exchange earnings.

From the multinomial logistic regression analysis, it is revealed that, being a female farmer, age, number of visits by extension officer, participation in credit, seed used, water harvesting, farm size and fertilizer application are factors that positively influence the probability of being a commercial farmer while factors such as education, seed expense, hired labor and labor expense are demotivating factors that affect the probability of farmers being commercial farmers. Though, they affect probability of market participation negatively, only seed expense were significant at $10 \%$ significant level.

From the findings discussed, it is worth to mention that, the intention of the government of Ghana to industrialize the country with the policy of "One Village One Dam and One District One Factory" that aim at transforming smallholder farmers from subsistence-oriented to commercial production which target both domestic and external markets is critical. However, effort should target at enhancing farmers' market participation since the majority of smallholders are not well integrated into the market system. Also, policy makers should integrate nonparticipant farm households to the market through the use of technical advice and capacity building training. The capacity building can take the form of land reallocation and subsidizing fertilizer as these factors positively impact commercial farmers' market participation.

As credit show to be positively related to market participation in all the farmer groups, providing an attractive and better credit services for households with appreciable land size could create a viable condition for them to join the market oriented farmers. Also, farmers who could not participate in the larger scale production due to inadequate capital could overcome their limitation and exit the subsistence farming group. The gender results show that, a farmer being a female is likely to sell more of the farm produce relative to being a male farmer. So, improving market participation across farmers in Ghana and related or similar countries, call for the need to focus on improving women's access to credit, land, education and training and provide information on market prices to motive female farmers into commercial agriculture.

\section{References}

[1] Tanko M, Iddrisu A, Alidu AF, 2015. Determinants of Rice Yield in Northern Region of Ghana, the Role of Policy, Asian Journal of Agricultural Extension, Economics \& Sociology, 9(2), 1-11, 2016.

https://www.researchgate.net/publication/287965057_Determi nants_of_Rice_Yield_in_Northern_Region_of_Ghana_the_Ro le_of_Policy.

[2] World Bank, 2016. World Tables. World Bank, Washington DC, USA. http://data.worldbank.org/data-catalog/worlddevelopment-indicators.

[3] Balint B, 2004. Institutional factors influencing agricultural sales of the Individual farmers in Romania. Conference on International Agricultural Research for Development, Berlin. http://citeseerx.ist.psu.edu/viewdoc/download?doi=10.1.1.116. $6754 \&$ rep $=$ rep $1 \&$ type $=$ pdf.

[4] Abbott C, 1987. Agricultural marketing for the developing world. Cambridge University Press. http://econpapers.repec.org/article/eeejfpoli/v_3a13_3ay_3a19 88_3ai_3a3_3ap_3a325-327.htm.

[5] Moti J, Berhanu G, Hoekstra D, 2009. Smallholder commercialization: Processes, determinants and impact. Discussion Paper No. 18. Improving Productivity and Market Success (IPMS) of Ethiopian Farmers Project, ILRI (International Livestock Research Institute), Nairobi, Kenya. 55. https://www.microlinks.org/sites/microlinks/files/resource/files/IL RI\%20-

\%20Smallholder\%20Commercialization\%20Processes.pdf. 
[6] Immink MDC, Alarcon JA, 1993. Household income, food availability, and commercial crop production by smallholder farmers in the western highlands of Guatemala. Economic Development and Cultural Change 41(2). https://cgspace.cgiar.org/bitstream/handle/10568/3015/workin gpaper_22.pdf?sequence $=2$.

[7] Pingali P, 1997. From subsistence to commercial production System: The transformation of Asian agriculture. Am. J. Agric. Econs; 79(2). http://econpapers.repec.org/article/oupajagec/v_3a79_3ay_3a1 997_3ai_3a2_3ap_3a628-634.htm.

[8] Strasberg PJ, Jayne TS, Yamano T, Nyoro J, Karanja D, Strauss J, 1999. Effects of agricultural commercialization on food crop input use and productivity in Kenya. Michigan State University International Development Working Papers No. 71. Michigan, USA. http://fsg.afre.msu.edu/papers/idwp71.pdf.

[9] Gabre-Madhin EZ, Alemu D, Samson D, 2007. From farmer to Market: Smallholder Commercialization of food crops in Ethiopia.

http://www.academicjournals.org/journal/JDAE/article-fulltext-pdf/12C322B57753.

[10] Von Braun, J., and E. Kennedy ed. 1994. Agricultural Commercialization, Economic Development, and Nutrition. Baltimore and London: The Johns Hopkins University Press.

[11] Wooldridge JM, 2002. Econometric Analysis of Cross Section and Panel Data. The MIT Press Cambridge, Massachusetts London, England (page 453-550). https://pdfs.semanticscholar.org/6bd0/adf734a194039061d085 202808e5a0763289.pdf.

[12] Ghana Statistical Service 2015. Ghana Statistica Service Annual Report 2015.
http://www.statsghana.gov.gh/docfiles/GDP/GDP2015/2015 Annual_GDP_September_2015_Edition.pdf.

[13] Demeke LB, Haji J, 2014. Econometric analysis of factors affecting market participation of smallholder farming in Central Ethiopia, Journal of Agricultural Economics, Extension and Rural Development, 2(6): 094-104, June, 2014. https://www.researchgate.net/profile/Leykun_Birhanu/publicat ion/299537456 Econometric analysis of factors affecting market_participation_of_smallholder_farming_in_Central_Et hiopia/links/56fe502c08ae1408e15cfd31.pdf.

[14] Cunningham LT, Brown BW, Anderson KB, Tostao E, 2008. Gender differences in marketing styles. https://mpra.ub.unimuenchen.de/56149/.

[15] Mahelet GF, 2007. Factors affecting Commercialization of Smallholder Farmers in Ethiopia. http://www.ifrj.upm.edu.my/23\%20(04)\%202016/(60).pdf.

[16] Mulatu D, Jayne TS, Kelly V, Said A, Levallee JC 1998. Agricultural market performance and determinants in Ethiopia. Grain market research project. http://fsg.afre.msu.edu/Ethiopia/index.htm.

[17] Erik M, Nivelin N 2002. Commercialization and Subsistence in Transaction Agriculture: Empirical Evidence from Albania, Bulgaria, Hungary and Romania Paper prepared for Presentation at the Xth EAAE Congress 'Exploring Diversity in the European Agri - Food System', Zaragoz a (Spain), 28-31 August. http://ageconsearch.umn.edu/bitstream/24786/1/cp02ma88.pdf.

[18] Balint B, 2005. Determinants of commercial orientation of individual farms Romania. Conference on International Agricultural Research for Development. Berlin. https://www.iamo.de/fileadmin/documents/dp113.pdf. 